\title{
LIRISMO VERSUS FORMALIDADE
}

\author{
Murilo Marcondes de Moura
}

USP

\begin{abstract}
RE S U M O
Este artigo procura revelar, sem negar a imagem consagrada do poeta, aspectos problemáticos e perturbadores da poesia de Manuel Bandeira. Nele, é recontada, sob uma ótica deslocada em relação às abordagens que a obra do poeta habitualmente recebe, a fábula - simbólica da relação do poeta com sua obra da superação, em que a robustez nasce da fraqueza.
\end{abstract}

PALAVRAS - CHAVE

Literatura Brasileira, Poesia Modernista, Manuel Bandeira.

"Sei, por experiência, que no Brasil todo sujeito inteligente acaba gostando de mim." A declaração de Manuel Bandeira, situada numa passagem irônica do Itinerário de Pasárgada, soa hoje como uma verdade das mais naturais, quase cinqüenta anos depois de proferida.

A aceitação unânime, digna de um clássico, não é certamente exclusiva de Bandeira em nossa literatura, mas poucos autores serão bem amados como ele, não apenas pela grandeza da obra, mas também pela simpatia que sempre inspirou sua figura humana. A identificação entre o escritor e o homem é, aliás, uma das manifestações mais poderosas desse encanto. Desse carisma o poeta parecia ter inteira consciência. A sua "atuação" no curta-metragem de Joaquim Pedro de Andrade, "O poeta do Castelo", consiste em marcar, sem afetação, a sua presença ao mesmo tempo próxima e encantada, tão semelhante à sua própria linguagem poética.

É provável que exista nos admiradores de Bandeira uma confiança não apenas no plano estético como também no plano moral, traduzida em um sentimento mais ou menos assim: com esse nós podemos contar, ele é daqueles que resistem com tenacidade, ancorados no cotidiano, mas, simultaneamente, identificados à fantasia poética. Ou, como escreveu ele mesmo a Mário de Andrade, entre altivo e sofrido: "[tenho] um orgulho safado de não comprazer com o sofrimento, de agüentar firme como os sujeitos que morrem no pólo".

No início de sua trajetória poética, que ele insiste ter sido desencadeada pelo "mau destino", lê-se, entre tantas fórmulas de sofrimento e de desamparo:

Minha janela desmantelada

Dá para o vale do desalento.

O trecho, assim como todo o poema que o contém ("Ruço"), embora sentido, é bastante artificial ao incorporar clichês retóricos de expressão da miséria individual. Desse artificialismo, por outro lado, brota uma musicalidade tão fácil e natural que a impessoalidade 
retórica se funde inextricavelmente à confissão íntima. O exagero, no caso, é tanto engenho poético quanto expressão intensa do sentimento.

Interessa, sobretudo, nesse pequeno trecho, desentranhar o retrato nele embutido: nada se diz diretamente do sujeito, mas dele tudo se revela, seja a partir do lugar de onde ele vê ("janela desmantelada"), seja a partir daquilo que vê ("vale do desalento"). A equivalência sonora dos dois versos, inclusive das palavras-chave que os compõem ("janela" // "vale"; "desmantelada" // "do desalento"), propõe uma equivalência evidente entre o sentimento interno de desânimo e a paisagem desolada.

Desse lugar arruinado, Manuel Bandeira iniciou o seu canto, que viria a ser um legado vigoroso e construtivo, moral e esteticamente, por ele próprio denominado de "palavra fraterna". Há na vida e na obra de Bandeira, portanto, a possibilidade de se extrair uma espécie de fábula da superação, em que a robustez nasce da fraqueza e, com discrição embora com firmeza, se impõe. Ou, como se lê em "Ariesphinx", que fornece outro retrato do poeta: "sotoponho/ O leão ao manso cordeiro".

Pretende-se aqui revisitar essa imagem tão apolínea de Manuel Bandeira, não para negá-la (ela é incontestável), mas para trazer à tona o que ela pode eventualmente esconder de problemático e de perturbador.

A visão da vida adulta como corrupção da infância é persistente em Manuel Bandeira e assume pelo menos uma outra manifestação: a da alienação do poético no mundo prosaico. O próprio autor aproximou, de modo direto, infância e poesia, em passagem célebre do Itinerário de Pasárgada: "O que há de especial nessas reminiscências [da vida infantil] é que, não obstante serem tão vagas, encerram para mim um conteúdo inesgotável de emoção. A certa altura da vida vim a identificar essa emoção particular com outra - a de natureza artística."

As duas, infância e poesia, estão investidas das mesmas qualidades: o raro e o distante (há ainda, em ambas, um traço forte de libertação). Tudo isso é coisa sabida, mas o fato é que contrasta frontalmente com "naturalidade" e "simplicidade" - as características mais manifestas da poesia do autor. Pois naturalidade e simplicidade deveriam provir não propriamente do raro e do distante, mas do apego ao trivial e ao próximo, de cuja aderência nasceria um modo de cantar direto e espontâneo.

Em Manuel Bandeira, a enorme discrição da linguagem abafa, assim, uma firme negatividade em relação ao cotidiano e ao presente imediato, já que estes representariam obstáculos sistemáticos tanto à aparição da poesia como à atualização daquela emoção infantil. Em outras palavras, o tom familiar e terno da poesia de Bandeira guarda uma enorme radicalidade, sendo, profundamente, "áspero e intratável”, ainda que modulado por uma enorme polidez. "Polidez" e "discrição" são termos vinculados a uma tendência clássica, em que a elaboração artística prevalece sobre o tumulto.

A imagem positiva de Manuel Bandeira, poeta vitorioso sobre o "mau destino", é sem dúvida verdadeira e, muito provavelmente, dominante, mas não seria de todo despropositado proceder pelo avesso, abandonando por um momento a naturalidade da linguagem do autor, a sua "palavra fraterna", para investigar o que ela tem de crispado e revoltoso.

O propósito primeiro é o de evitar a trilha batida, já não com a pretensão de revelar algo novo sobre um autor tão bem estudado, mas para demorar a vista em uma ou outra 
minúcia talvez menos cuidada. Outra vantagem possível dessa perspectiva pode ser a de combater uma visão superficial do modernismo do poeta, encarado algumas vezes, sem grandes mediações, como adesão quase festiva ao cotidiano, quando na verdade se dispôs a ser uma crítica dele, e crítica a mais funda possível, já que efetuada desde dentro, isto é, pela incorporação dos próprios elementos do cotidiano.

Nesse sentido, "Poema tirado de uma notícia de jornal", "Balada das três mulheres do sabonete Araxá", entre tantos outros poemas, mostram antes um trabalho sistemático da poesia contra a linguagem jornalística, da propaganda etc. "Anti tudo o que é pau e pífio", conforme escreveu o próprio poeta em homenagem a Murilo Mendes.

Do pau e do pífio a poesia de Manuel Bandeira se ocupou muito (inclusive por visar tanto o "alumbramento" e o raro), e uma de suas encarnações mais recorrentes - não por acaso alvo das mais persistentes aversões do poeta - está no que poderíamos denominar de "espírito de gabinete". Um dos alvos deste breve estudo será o de investigar, na obra de Bandeira e como algo a ela essencial, o confronto entre a largueza intrínseca à palavra poética e o cerceamento inerente aos regulamentos e às convenções.

Lembre-se, como introdução ao problema, de "Na rua do sabão", poema em que os obstáculos à confecção, à soltura e à ascensão do balão do "tísico José", "filho da lavadeira", são enumerados e superados um a um. O último deles, antes do balão liberar-se "muito serenamente" daquele universo restrito, talvez seja o mais insidioso e detestável - a última amarra a ser vencida até a emancipação final nas "águas puras do mar alto" (imagem que conjuga novamente o raro e o distante como libertação):

Um senhor advertiu que os balões são proibidos pelas posturas municipais.

O contraste é flagrante entre o prosaísmo rasteiro do verso, com sua carga de constrangimento legal, e a liberação trazida pelo verso final, que pode ser associado tanto à fantasia infantil quanto à imaginação artística. A "vitória" dessas duas últimas, na breve narrativa que o poema propõe, não deve nos levar a subestimar o peso das "posturas municipais". ${ }^{1}$

As convenções fossilizadas, as atitudes meramente protocolares, a mentalidade burocrática aparecerão, de diferentes modos, em vários poemas e em diversas passagens da prosa do autor, sempre como objeto de repulsa e escárnio (quem sabe não resida aqui a raiz da aversão do individualista Manuel Bandeira ao comunismo soviético? ${ }^{2}$ ).

Algumas dessas ocorrências são apenas avulsas e fragmentadas, das quais o poeta extrai efeitos que vão do cômico ao pungente. Eis alguns exemplos, todos da obra poética: os "fragmentos do hino da bandeira", que se misturam ao mais esquivo devaneio, em "Noturno da Rua da Lapa"; as "pálidas meninas uniformizadas", de "Flores murchas"; a

\footnotetext{
${ }^{1}$ A propósito do poema "Na rua do sabão", ver a bela leitura de Marcus Vinícius Mazzari, "Os espantalhos desamparados de Manuel Bandeira”. Revista de Estudos Avançados da USP, n. 44, vol. 16, jan./abril 2002, p. 255-276.

${ }^{2} \mathrm{Na}$ curiosa crônica intitulada "Outra criatura" (de Flauta de papel), Bandeira afirma: "Ninguém pode negar a beleza da ideologia marxista. Mas ela foi corrompida na Rússia por uma política verdadeiramente celerada". Em seguida, o poeta se refere aos processos de expurgo, sugerindo o absurdo de um estado de terror amparado pela burocracia.
} 
indesejável "obrigação de voto", no segundo "Belo belo"; a curiosa "mão protonotária", do "Poema para Santa Rosa"; a reveladora decisão de utilizar a linguagem de tabelião para "despoetizar" Gonçalves Dias, no famoso "O nome em si" etc.

No poema "Oração a Nossa Senhora da Boa Morte", ao recorrer, no auge do desamparo, a Santa Rita dos Impossíveis, o sujeito é "despachado de mãos vazias". A linguagem de cartório tem aqui tal precisão, o seu efeito cômico é tão justo, que o leitor se esquece de que ela é uma das variações das "posturas municipais", vinculada, no caso, a um motivo fundamental em Bandeira: o do mal-amado.

Um dos momentos mais agudos e manifestos dessa postura refratária ao convencionalismo, entendido este como codificação cartorial da vida, está no poema "A Virgem Maria":

O oficial do registro civil, o coletor de impostos, o mordomo da Santa Casa e [o administrador do cemitério de São João Batista

Cavaram com enxadas

Com pás

Com as unhas

Com os dentes

Cavaram uma cova mais funda que o meu suspiro de renúncia

Depois me botaram lá dentro

E puseram por cima

As Tábuas da Lei

Ao que parece, temos no longo verso inicial um resumo da vida, a partir da enumeração de agentes da burocracia. Um sumário terrível (espécie de curriculum vitae) do nascimento à morte, ou melhor, da certidão de nascimento ao atestado de óbito (ou espécie de documento de enterro). A existência está inteiramente submetida à burocracia, e as "Tábuas da Lei" pesam sobre ela como uma lápide. A aversão à burocracia está atrelada aqui a outro motivo recorrente na lírica de Manuel Bandeira, e decerto um dos mais graves - o do enterrado vivo ("em verdade estou morto ali", afirma ele no "Poema de finados").

Expressão intensificada de tal soterramento, o verso seguinte tinha de estar tão cheio de palavras, as quais funcionam como blocos acumulados sobre o sujeito, lançado ao isolamento mais estrito:

Mas de lá de dentro do fundo da treva do chão da cova

Nesse caso, porém, nem que seja de um modo difícil de precisar (entre o patético e o zombeteiro?), ocorre de fato a ajuda de uma santa:

Eu ouvia a vozinha da Virgem Maria

Dizer que fazia sol lá fora

Dizer in siste n te m e n te

Que fazia sol lá fora.

A fala da Virgem Maria evoca, por sua vez, o famoso dístico de "Rondó dos cavalinhos":

O sol tão claro lá fora,

E em minh'alma - anoitecendo! 
Nas duas passagens observa-se um desacerto estrutural entre o dentro e o fora. Essa dissonância é atribuída normalmente ao gauche drummondiano ou ao sentimento de "exílio" em Murilo Mendes, mas não é menos forte em Manuel Bandeira, embora neste, como já foi dito, o desconcerto muitas vezes encontre uma expressão serena, por isso mesmo passível de ser confundida com "resolução" do conflito.

A propósito de tensões, a obra de Bandeira traz inúmeros antídotos ao abafamento da vida pelo "espírito de gabinete" ou pela mentalidade burocrática. Por exemplo, no desregramento do "Rondó do Palace Hotel" ou de "Não sei dançar", poemas em que a festa (especialmente o carnaval, de que o poeta concebeu um livro inteiro) é o núcleo. Mas há outro tipo de desregramento, nascido de momentos em que o poeta se sentia "mofino" ou "aporrinhado", com o conseqüente impulso irrefreável e algo perverso de perturbar a rotina.

Um dos poemas mais famosos de Bandeira nasceu numa circunstância dessas - "Voume embora pra Pasárgada" (o título inicial era precisamente "Rondó do aporrinhado"). Transcrevo abaixo uma das passagens de maior desafogo do poema:

Vou-me embora pra Pasárgada

Aqui eu não sou feliz

Lá a existência é uma aventura

De tal modo inconseqüente

Que Joana a Louca de Espanha

Rainha e falsa demente

Vem a ser contraparente

Da nora que nunca tive

A felicidade é identificada na estrofe a desimpedimento em sentido amplo. A expressão "aventura inconseqüente", redundante em sua postulação libertária, é, nesse sentido, a mais desafiadora. Não por acaso, há uma subversão das relações de parentesco, como se sabe algo que regula fundamentalmente as relações sociais. A gratuidade e a ausência de finalidade prevalecem, desencadeando o sentimento de "libertinagem" e o riso, que se impõem como desafio ao mundo uniforme e previsível.

O "mundo às avessas" de Pasárgada instaura algo semelhante ao que Murilo Mendes chamou, no poema "Mapa" (em ambos, trata-se de uma "geografia" alternativa), de "estado de bagunça transcendente", em que os maiores disparates são possíveis, como alguém ser, ao mesmo tempo, "louca" e "falsa demente", estranho e familiar, e assim por diante.

A irritação, que levou o poeta a escrever "Vou-me embora pra Pasárgada" (o verso que dá título ao poema, e que foi o seu ponto de partida, é uma fórmula de desabafo ou de exorcismo), está por detrás de muitas produções da arte moderna, como nos frottages de Max Ernst, para citar um artista raramente associado a nosso poeta. Ernst afirmava que o procedimento do "frottage" se fundamentava na "irritabilidade das faculdades do espírito por meios técnicos apropriados, que excluem toda condução mental consciente". ${ }^{3}$ É claro que a utilização da "escrita automática" nunca foi sistemática em Bandeira, mas um sentimento e mesmo uma atitude permanente de revolta podem irmaná-lo a artistas da linhagem de Ernst.

Além do mais, já se tornou lugar comum atribuir à arte moderna uma forma de resistência à visão cristalizada, no sentido de desautomatizá-la. Não é outra coisa o que fez

${ }^{3}$ Cf. "Au-delà de la peinture". In: Ecritures. Paris: Gallimard, 1970, p. 244. 
Manuel Bandeira no já citado "Poema tirado de uma notícia de jornal". Mais forte ainda é o sentido de desautomatização presente em "Momento num café”, para citar apenas mais um exemplo. A divisão do poema em duas partes nítidas opõe dois modos de ver a morte (e, em conseqüência, de ver a vida). Assim, ao "maquinalmente" da primeira estrofe, revelador de uma visão superficial, se opõe o "gesto largo e demorado" da segunda, reflexivo e complexo. Recorde-se, a propósito, uma passagem curiosa em que Bandeira vincula, sem mediações, "raiva" da visão burguesa e adesão à "poesia moderna". ${ }^{4}$

O que se observa, portanto, é uma aproximação estreita entre comportamento (refratário à rotina) e linguagem (aberta aos experimentalismos). ${ }^{5}$ Os jogos verbais, aprendidos com o pai, que os denominava de "óperas", são bons exemplos da perturbação da linguagem como reação ao estreito e unilateral ou à codificação simplificadora e unívoca da vida. Num dos primeiros textos em prosa de Bandeira, intitulado "Por amor de um verso" (1917), o poeta sustenta uma polêmica acesa sobre ritmo e verso, condenando, sintomaticamente, em seu opositor, a "mesquinha empresa de substituir leis mecânicas e imóveis à vida sempre renovada e variada".

Retornando às brincadeiras verbais que o poeta herdou do pai (não deixa de ser "bandeiriano", isto é, terno e discreto, aprender rebeldia com o pai ao invés de se rebelar diretamente contra ele...), cabem ser transcritas pelo menos duas declarações do poeta. Trata-se de trechos de cartas a Mário de Andrade, que mostram como algo do impulso libertário do poeta pode ser associado a esse aprendizado doméstico:

"Se meu pai fosse vivo você não teria leitor mais gozado para a sua história. Ele era doido por esse lirismo essa graça essa sacanagem esse verbalismo popular."

"Desde abril não fazia um verso, e devo dizer que tive muito prazer em compor essa brincadeira, me lembrando daqueles surrealismos em que meu pai desrecalcava o seu lirismo de engenheiro aporrinhado pela vida de escritório."”

Esse último trecho é notável por duas associações muito sublinhadas aqui: fazer poético e infância (se não bastasse a referência ao pai, o termo utilizado é "brincadeira"...); fazer poético e desrecalque, e desrecalque precisamente de duas rotinas ou atividades muito associadas ao monótono e ao unilateral: a do engenheiro e a do funcionário público.

\footnotetext{
${ }^{4}$ Em carta a Mário de Andrade, de outubro de 1922, lê-se: "Ora eu sou sapo-cururu, adorador da Lua em todas as fases. Mas detesto ver a adoração burguesa e soi disant poética da Lua e outras coisas nobremente sentimentais: o ideal, as ilusões que não voltam mais, as quimeras etc.

Daí a raiva. É preciso desgostar essa gente dessas coisas. É por aí que a poesia moderna me satisfaz plenamente." (Grifos do próprio Bandeira).

${ }^{5}$ A propósito do vínculo entre transgressão estética e comportamento, é interessante mencionar o desapontamento do tio de Manuel Bandeira, Raimundo Bandeira, com quem o poeta dialogava sobre poesia desde muito novo. Ele encarou a "passagem" de Bandeira ao modernismo como uma "degradação artística do sobrinho": "Sinto a mesma sensação de tristeza que teria se soubesse que você tinha dado para bêbado ou pederasta". Apud Francisco de Assis Barbosa, Manuel Bandeira 100 anos de poesia. Recife: Pool editorial, 1988, p. 56.

${ }^{6}$ Carta de 23 de agosto de 1928, em que Bandeira comenta Macunaíma, que ele elogia principalmente por esse aspecto lúdico ou de "brincadeira verbal".

${ }^{7}$ A carta, de 3 de dezembro de 1935, dava notícia do poema "Trem de ferro", então recém escrito e depois incluído em Estrela da manhã.
} 
Um dos poemas de Manuel Bandeira mais identificados à revolta talvez seja também um de seus poemas lidos do modo mais esquemático: "Poética". Ele foi quase confiscado da obra do autor para se tornar um exemplo da "poética" geral do movimento modernista (o que é verdadeiro apenas em parte). Relido a partir dos conflitos aqui observados, o poema é um dos mais obsessivos na afirmação da liberdade como recusa sistemática das convenções.

Estou farto do lirismo comedido

Do lirismo bem comportado

Do lirismo funcionário público com livro de ponto expediente protocolo e

$(\ldots)$

[manifestações de apreço ao sr. diretor.

Quero antes o lirismo dos loucos

O lirismo dos bêbedos

O lirismo difícil e pungente dos bêbedos

O lirismo dos clowns de Shakespeare

- Não quero mais saber do lirismo que não é libertação.

Assim como Bandeira aprendeu com o pai os nonsenses verbais, acredito que tenha aprendido com o seu primeiro crítico, João Ribeiro, o essencial do que está dito em "Poética" (Bandeira foi um inovador a partir da escuta e da incorporação da tradição e não da recusa intempestiva desta). Leiam-se as seguintes afirmações do antigo professor de Bandeira no Colégio Pedro II, em texto sobre A cinza das horas: "A poesia não pode ser obtida por formulários, tabelas, e por precauções antecipadas de rimas e vocábulos" e "A verdadeira arte não comporta compendiosas retóricas, e a verdadeira poesia não tem arte poética".

A vida mais conforme à excessiva formalidade e ao regulamentar, aquela mais contrária ao "lirismo dos loucos", "dos bêbedos" e "dos clowns de Shakespeare" é provavelmente a militar. Contra ela, o poeta escreveu um libelo discreto embora terrível em "O major".

O poema é outro "conto cruel" proposto pelo poeta, em que a vida inteira se resume drasticamente ao toque de silêncio no enterro. Outra vez, Bandeira, a partir da morte (da "boca do túmulo"), extrai um saber sombrio sobre a vida; mais do que nunca "uma agitação feroz e sem finalidade", sobretudo quando se trata do enterro de um "homem de ação".

Como sempre, porém, há outros modos de ler o poema, em especial pelo motivo do ascetismo, que permite associá-lo ao famoso soneto "O lutador", quase integralmente "sonhado" pelo poeta. Ao contrário deste, porém, de expressão elevada e de arremate sublime, "O major" traz embutida uma lição de estilo: trata-se da "anti-ênfase" ("apenas ... o toque de silêncio", reforçada ainda pela personificação já cristalizada pelo hábito, mas que não escapou ao poeta: "boca do túmulo") - expressão de Rachel de Queiroz para designar o próprio Manuel Bandeira. Como recusa de qualquer heroísmo e da retórica a ele correspondente, o poema toma o partido dos tons mais baixos e da música de câmara, herança talvez do Bandeira crepuscular dos primeiros livros.

Mas o poema mais revelador no que se refere à questão do militarismo, tomado aqui como paroxismo da obediência estrita aos regulamentos ou às "posturas municipais", e também um dos mais perturbadores de toda a obra de Bandeira, é o "Noturno da Parada Amorim”, cuja leitura será capaz de recuperar o núcleo das idéias discutidas até aqui. 
O violoncelista estava a meio do concerto de Schumann

Subitamente o coronel ficou transportado e começou a gritar: - Je vois des

[anges! Je vois des anges! - E deixou-se escorregar sentado

O telefone tilintou.

[pela escada abaixo.

Alguém chamava?... Alguém pedia socorro?...

Mas do outro lado não vinha senão o rumor de um pranto desesperado!...

(Eram três horas.

Todas as agências postais estavam fechadas.

Dentro da noite a voz do coronel continuava gritando: - Je vois des anges! Je

[vois des anges!)

O poema foi "desentranhado" de uma história contada ao poeta pelo violoncelista Emil Simon, irmão de Frédérique Simon Blank - a Moussy, que segundo Francisco de Assis Barbosa foi a "grande afeição" da vida de Bandeira ${ }^{8}$. Ouçamos o poeta: "Esse poema tem uma gênese muito complicada. O ponto de partida foi um fato real. Numa recepção em Bruxelas, o violoncelista Emil Simon, meu amigo, já falecido, tocava o concerto de Schumann, quando um coronel do exército belga, que ouvia a música no patamar e estava meio bêbedo, ficou transportado, e começou a se agitar, dizendo: 'Quels sont ces sons célestes que j'entends? Il faut que je fasse quelque chose'. O que achou melhor de fazer foi sentar-se na escada e deixar-se escorregar por ela abaixo. Misturei isso com a impressão que sempre me causou uma agência postal fechada - por quê? Sei lá - e certas telefonadas alta madrugada, e os descampados dos subúrbios da Leopoldina..."

A reação do adulto militar - escorregar escada abaixo, gritando que estava em presença de anjos, é enigmática e também comicamente inadequada. Não há como deixar de associá-la a um comportamento "infantil", como se este fosse a melhor resposta ao misterioso apelo trazido pela música de Schumann. A história deve ter impressionado muito o poeta porque entrelaça intimamente atributos da infância, da arte e da religião: pureza, espontaneidade, enlevo, que podem ser sintetizados num dos termos essenciais da "mitologia pessoal" de nosso autor - "alumbramento".

Por outro lado, o poema, embora narre uma história de êxtase ou de plenitude, se define antes pela dificuldade ou mesmo pela impossibilidade de diálogo. Às relações problemáticas entre a vida adulta e a infância, entre a disciplina severa e a naturalidade, entre o profano e o sagrado, o poema justapõe imagens em que a incomunicabilidade predomina: "O telefone tilintou (...) Mas do outro lado não vinha senão o rumor de um pranto desesperado". ${ }^{10}$, "Todas as agências postais estavam fechadas".

\footnotetext{
${ }^{8}$ Esta informação certamente importa muito pouco para a compreensão do poema, mas talvez possa ajudar a explicar a sua atmosfera de "irrealização", pois "Noturno da Parada Amorim" também trata, a sua maneira, de "desejos irrealizáveis" - expressão do próprio poeta para interpretar outro de seus poemas estranhos, e de temática diretamente erótica - "Canção das duas índias".

${ }^{9}$ Cf. Paulo Mendes Campos, "Reportagem literária". In: Sônia Brayner (org.). Manuel Bandeira. Rio de Janeiro: Civilização brasileira, 1980, p. 91.

${ }^{10}$ João Alphonsus escreveu um ensaio curiosíssimo em que busca estudar o "complexo do telefone" em Manuel Bandeira. "Quase toda vez que o poeta joga com o inconsciente, faz sondagens surrealistas, lá vem o telefone". Além do "Noturno da Parada Amorim, são mencionados outros
} 
Ao encerrar o poema com a permanência da voz do coronel, a situação de insolubilidade se perpetua (como "um insolúvel flautim" na "noite escassa", para lembrar Carlos Drummond de Andrade em um de seus também numerosos e enigmáticos noturnos). O próprio título do poema, que se refere a uma parada de trem entre Rio de Janeiro e Petrópolis (lugares fundamentais para a história da poesia de Bandeira e entre os quais ele certamente devia observar certo antagonismo), acaba por impregnar-se desse mesmo sentido de trânsito interrompido ou travado entre dois pólos.

"Pois é este homem lógico, com mania de se certificar exatamente das coisas, que escreve alguns dos poemas mais estranhos da poesia brasileira: "Noturno da Parada Amorim", "Noturno da rua da Lapa", "Palinódia". Estranhos justamente pela palpitação vaga, indefinível, incompreensível que os percorre. Poesia cósmica que se sente mas não se compreende, talvez mais inexprimível do que a de Arthur Rimbaud".

Essa afirmação de Affonso Arinos de Mello Franco ${ }^{11}$ não é isolada. Ribeiro Couto, por exemplo, mencionando "Noturno da Parada Amorim" e "Noturno da rua da Lapa", refere-se a "episódios misteriosos", poemas que "insinuam malestar, pavor, como vozes estranhas murmurando queixas e sarcasmos numa noite escura". ${ }^{12}$

Adolfo Casais Monteiro, por sua vez, enumera um "grupo de poemas" de Bandeira "A virgem Maria", "Noturno da Parada Amorim" e "Noturno da rua da Lapa" -, em que se distingue "a quebra total com a realidade cotidiana, com o 'mundo acordado', com qualquer forma de discursividade verbal - e, portanto, racional". ${ }^{13}$

Ao circunscrevermos, ao longo deste texto, momentos da obra de Bandeira em que se observa o desafio mais ou menos aberto às "posturas municipais", acabou-se por enfatizar também a natureza mais esquiva e hermética de sua lírica. Em princípio, os momentos aqui observados parecem contrariar o projeto do próprio autor, que declarou, no Itinerário de Pasárgada: "Só não fui claro quando não pude".

Trata-se de uma declaração em princípio estranha para um poeta moderno e culto, como foi Manuel Bandeira. Mas, como é óbvio, ele jamais associou "clareza", em poesia, à comunicabilidade imediata, como outra de suas declarações vem, em tempo, esclarecer: "Os lados incompreendidos de um poema não lhe prejudicam a beleza". O mais verdadeiro, portanto, é refletir sobre a obra do poeta a partir das tensões entre o crispado e o acolhedor, hermetismo e acessibilidade, transgressão e incorporação.

Na busca justamente de um retrato mais íntegro de Manuel Bandeira, Adolfo Casais Monteiro propôs algumas aproximações extravagantes: "Um Nerval que tivesse o dom da ironia e do sarcasmo; um Antônio Nobre que soubesse sair da torre da doença e amar a vida apesar de tudo; um Paul Valéry a quem fosse dado chorar; um clássico sabendo viver

poemas entre os mais herméticos do poeta, como "Palinódia" e "O desmemoriado de Vigário Geral". Para João Alphonsus, sobretudo no "Noturno da Parada Amorim", o telefone "exprimiria todo o inatingido, de preferência com I maiúsuculo". Cf. "O telefone na obra de Manuel Bandeira". In: Homenagem a Manuel Bandeira. São Paulo: Metal Leve, 1986, p. 97-100.

${ }^{11}$ Homenagem a Manuel Bandeira, op. cit , p. 45.

${ }^{12}$ Dois retratos de Manuel Bandeira. Rio de Janeiro: São José, 1960, p. 23.

${ }^{13}$ Manuel Bandeira. Rio de Janeiro: MEC, 1958, p. 40. 
profundamente todos os delíquios românticos, e um modernista amando o sabor de tornear uma bela estrofe de rigorosa geometria". ${ }^{14}$

Quem sabe, afinal, a crítica sistemática aos regulamentos e protocolos (que a vida militar encarna como nenhuma outra) não tenha implicado uma espécie de revanche em relação à própria vida do poeta, disciplinadíssimo em decorrência da doença, para quem o quarto era uma espécie de "enfermaria" (Ribeiro Couto), de "prisão" ou de "convento" (Sérgio Buarque de Holanda). O próprio Bandeira afirmou a Mário de Andrade, entre jocoso e sério, em carta de maio de 1932: "Ora, eu sou um tísico disciplinado. Em arte sou individualista, mas em matéria de tuberculose funciono sempre socialmente".

Mas é esse mesmo individualista que em 1966, aos 80 anos, escreveu na introdução a uma antologia "popular" de sua obra poética: "foi para levar aquela palavra fraterna aos que ainda não me leram e não têm dinheiro para comprar senão livros acessíveis que aceitei o convite para organizar este volume". ${ }^{15}$

Entre individualismo e acessibilidade, entre transfiguração e autobiografia, Manuel Bandeira propôs as intersecções mais insuspeitadas. Nele a obscuridade se mescla à transparência "fraterna" da fala, "como o céu escuro recebe a companhia das primeiras estrelas".

\section{A}

\section{A B STRACT}

Not disregarding the poet's consecrated image, this article discusses problematic and disturbing aspects in Manuel Bandeira's poetry. From a viewpoint that is distinct from those perspectives usually employed in the study of this particular poet, the article revises the fable - symbolic of the poet's relation to his work - about overcoming, in which strength derives from weakness.

\section{KEYWORDS}

Brazilian Literature, Modernist Poetry, Manuel Bandeira.

\section{REFERÊNCIAS BIBLIOGRÁFICAS}

ALPHONSUS, João. O telefone na obra de Manuel Bandeira. In: Homenagem a Manuel Bandeira. São Paulo: Metal Leve, 1986. p. 97-100.

ANDRADE, Mário de, BANDEIRA, Manuel. Correspondência. São Paulo: Edusp, 2000.

BANDEIRA, Manuel. Itinerário de Pasárgada. Rio de Janeiro: Nova Fronteira, 1984.

BANDEIRA, Manuel. Meus poemas preferidos. Rio de Janeiro: Ediouro, 1998.

BANDEIRA, Manuel. Flauta de papel. In: Poesia completa e prosa. Rio de Janeiro: Nova Aguilar, 1990. p.473-535.

${ }^{14}$ Op. Cit., p. 47

${ }^{15}$ Cf. Meus poemas preferidos. Rio de Janeiro: Ediouro, 1998, p. 14. 
BARBOSA, Francisco de Assis. Manuel Bandeira 100 anos de poesia. Recife: Pool Editorial, 1988.

CAMPOS, Paulo Mendes. Reportagem literária. In: BRAYNER, Sônia (Org.). Manuel Bandeira. Rio de Janeiro: Civilização brasileira, 1980.

COUTO, Ribeiro. Dois retratos de Manuel Bandeira. Rio de Janeiro: São José, 1960.

ERNST, Max. Au-delà de la peinture. In: Ecritures. Paris: Gallimard, 1970.

MAZZARI, Marcus Vinícius. Os espantalhos desamparados de Manuel Bandeira. Revista de Estudos Avançados da USP, São Paulo, n. 44, v. 16, jan.-abr., 2002, p.255-276.

MELLO FRANCO, Affonso Arinos de. Manuel Bandeira ou o homem contra a poesia. In: Homenagem a Manuel Bandeira. São Paulo: Metal Leve, 1986. p.35-46.

MONTEIRO, Adolfo Casais. Manuel Bandeira. Rio de Janeiro: MEC, 1958. 